\title{
Using informed consent to save trust
}

\author{
Nir Eyal
}

Correspondence to

Dr Nir Eyal, Program in Ethics and Health, Harvard University, Boston, MA 02139, USA; nir_eyal@hms.harvard.edu

Received 2 January 2012 Revised 16 July 2012 Accepted 1 November 2012 Published Online First 8 December 2012

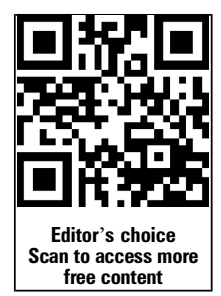

\section{SLinked}

- http://dx.doi.org/10.1136/ medethics-2012-101206 - http://dx.doi.org/10.1136/ medethics-2012-101207 - http://dx.doi.org/10.1136/ medethics-2012-101208

\section{ABSTRACT}

Increasingly, bioethicists defend informed consent as a safeguard for trust in caretakers and medical institutions. This paper discusses an 'ideal type' of that move. What I call the trust-promotion argument for informed consent states:

1. Social trust, especially trust in caretakers and medical institutions, is necessary so that, for example, people seek medical advice, comply with it, and participate in medical research.

2. Therefore, it is usually wrong to jeopardise that trust.

3. Coercion, deception, manipulation and other violations of standard informed consent requirements seriously jeopardise that trust.

4. Thus, standard informed consent requirements are justified.

This article describes the initial promise of this argument, then identifies challenges to it. As I show, the value of trust fails to account for some commonsense intuitions about informed consent. We should revise the argument, commonsense morality, or both.

\section{THE TRUST-PROMOTION ARGUMENTFOR INFORMED CONSENT}

As I understand the standard requirement of informed consent, it states,

roughly, [that] when a sufficiently capacitated adult does not give sufficiently informed and voluntary consent to intervention in her body or her private sphere, then, at least when the intervention is substantial, not trivial, and absent severe jeopardy for third parties, the intervention is impermissible. ${ }^{1}$

Commonsense morality includes additional specifications, as to who counts as sufficiently capacitated, when consent is sufficiently informed, and so forth. This article explores how much the fully specified standard requirement may rest on the need to protect public trust in the medical system. Bioethicists increasingly invoke that need as a major ground for informed consent. In Autonomy and Trust in Bioethics, Onora O'Neill writes, 'Informed consent... is generally important (inter alia) because it can make a distinctive contribution to the restoration of trust. ${ }^{2}$ O'Neill follows Torbjörn Tännsjö, Jennifer Jackson and other bioethicists who have cited the need to build and maintain trust as reason to demand informed consent for clinical care. ${ }^{3}{ }^{4}$ In 'Trust, The fragile foundation of contemporary biomedical research,' Nancy Kass and colleagues defend informed consent to research participation similarly. They explain that 'Maintaining public trust is absolutely crucial to the research enterprise. ${ }^{5}$ For Ruth Faden and colleagues, 'institutional review boards (IRBs) and investigators that (do not pay) attention to the process of consent... run the risk of undermining... trust. ${ }^{6}$ Additional authors cite trust as a ground for rigorous informed consent procedures in medical trials. ${ }^{7-9}$

The value of public trust has also been invoked against specific transgressions of informed consent. Sissela Bok's early writing mobilises the risk to public trust against 'policies of shading the truth (in deceptive psychological research), which are opposed to what must remain informed consent;' she expresses frustration that 'advocates of deceptive research... rarely even take into account the risk of damaging the climate of trust in which they have to operate. ${ }^{10}$ The same concern for public trust underwrites her opposition to deceptive placebo prescription:

The trust of those patients who find out they have been duped is lost, sometimes irretrievably. They may then lose confidence in physicians and in bona fide medications which they may need in the future. They may obtain for themselves more harmful drugs or attach their hopes to debilitating fad cures. ${ }^{11}$

New work continues to link informed consent with trust, ${ }^{12}$ and this linkage seems to resonate with the wider community. In a focus group of African-American Washington DC area residents on how to increase study enrolment in their community,

Several participants emphasized the need for full and honest disclosure of information before a study begins... The group members suggested [a] key reason for informed consent: to help build a relationship of trust between researcher and participant. $^{13}$

Surprisingly, the link to trust is virtually absent from most textbook discussions of the case for informed consent. This article fills this lacuna by starting a more systematic assessment of that link.

Some of the bioethicists mentioned above are Kantian, some are consequentialist, and some are practice-oriented without foundational commitments. Their views on informed consent and on its relation to trust differ in scope, detail, putative urgency and otherwise. Rather than attempting exegesis and examination of each authorâs special way of linking informed consent and trust, I shall chart and then examine a simplified and straightforward way to link them. This abstraction seems to me more fruitful. Physicists who explore movement also find it fruitful to abstract from moving objects' colours, from friction and from other complicating factors. The ideal type that I shall examine can be called the trust-promotion argument for informed consent. It states:

1. Social trust, especially trust in caretakers and medical institutions, is necessary so that, for 
example, people seek medical advice, comply with it and participate in medical research.

2. Therefore, it is usually wrong to jeopardise that trust.

3. Coercion, deception, manipulation and other violations of standard informed consent requirements seriously jeopardise that trust.

4. Thus, standard informed consent requirements are justified.

Although non-utilitarians can certainly use the trustpromotion argument, the argument is potentially utilitarian. It defends informed consent as an instrument to an important social good-trust in caretakers and medical institutions and, more broadly, social trust. The argument is different from backward-looking trust-based arguments, which defend informed consent as an intrinsically valuable way to honour the trust that the patient has placed in the doctor, or as an intrinsically valuable expression of virtuous trustworthiness. ${ }^{14-18}$ Finally, the argument differs sharply from the argument that informed consent is important because it is naïve to trust doctors to decide for oneself.

This article shows both the initial attraction and the challenges facing the trust-promotion argument. In its present form, I shall contend, the argument fails to ground the requirement of informed consent as commonsense morality construes that requirement. Either the argument or commonsense intuitions require revision.

\section{THE INITIAL PROMISE OF THE ARGUMENT}

The trust-promotion argument is an 'ideal type' that links trust to informed consent in a simple way, facilitating a systematic assessment of that link. The link merits assessment not only because bioethicists make it, but for three additional reasons. Trust matters a lot, especially in medical settings; informed consent seems initially to protect it in several channels; and alternate arguments for informed consent are currently in hot water. Let me elaborate.

The importance of trust goes far beyond the clinical setting. Social capital literature often argues that 'high-trust' societies, where mutual trust and trust in institutions flourish, tend to have stronger economies and democracies than 'low-trust' ones. The social determinants of health literature emphasises the value of mutual trust as a contributor to population health. Thus if medical practice and investigation are particularly vulnerable to loss of trust, then it would seem appropriate to warn about the 'critical role of trust' in doctors and medical researchers. $^{6} 1719$ For a glimpse into what a breakdown of trust in clinicians can do in clinical settings alone consider widespread recent refusals to let clinicians administer the MMR and polio vaccinations, in both developing and developed countries. In short, trust can matter a lot for the public and its health.

Moreover, violations of informed consent may be thought to deepen an existing 'crisis of trust', ${ }^{20}$ through several channels. First, patients who realise that doctors sometimes impose unwanted medical interventions might stop trusting doctors not to impose them, and stay away from doctors, out of fear. ${ }^{7} 2122$ Second, a doctor's lies and deceit may undermine trust in the doctor's and officials' veracity-and advice. ${ }^{4} \quad 10 \quad 11$ Third, imposed care, lies and other violations of real or perceived informed consent duties can antagonise patients, thereby instigating suspicion, negative feelings, low rapport and general doubt about the doctor's and officials' good will, competence and advice, with impact on adherence. Our trust in someone rests partly on our sense that he or she is a decent person who respects basic moral duties. ${ }^{23}$ Fourth, informed consent may be a ritualistic expression that helps bolster mutual trust. ${ }^{24}$ In these or in other channels, informed consent, trust and the good effects of trust may be thought to be bound up. Indeed, patients who rate physicians lower on participatory decision-making-a component of fully informed consent-are more likely to disenroll from a treatment practice over 1 year-perhaps reflecting diminished trust-leading to outcomes such as lower adherence to blood pressure treatment. ${ }^{25} 26$

To illustrate both how important trust in the medical system can be and how that trust may depend on informed consent, consider

African-American mistrust of the medical community in general and medical research in particular. The absence of trust has emerged as a stumbling block in efforts to include African-Americans in clinical research. ${ }^{27}$

Low research participation among African-Americans probably delimits doctors' understanding of the impact of disease and medicine in that population. ${ }^{27-30}$ Similar mistrust partly accounts for relative paucity of visits to doctors and dentists ${ }^{31}$; for low adherence to medical advice ${ }^{30}$; for relatively low rates of organ and blood donation and availability ${ }^{32}{ }^{33}$; and for low rates of care withdrawal at the end of life. ${ }^{34} 35$ In a nutshell, distrust of the medical community is one factor setting back African-Americans' average health outcomes and quality of life. That distrust has deep roots and justifications, ranging from slavery through Tuskegee to continuing disparities. ${ }^{36}$ However understandable, it arguably affects many contemporary African-Americans more adversely than beneficially. ${ }^{36}$ Part of the promise of informed consent lies in the hope that it will warrant and save trust in medical institutions and in individual caretakers. Visibly enforced informed consent practices signal to patients that they, and not doctors, will have the final say; for instance, that trial participation and clinic visits do not risk unwanted intervention. It is for such reasons that the abovequoted study concludes, 'Most recently, the question has been raised of waiving consent for some areas of clinical investigation... We advocate extreme caution in populations such as the African-American community...,27

A final reason why we should examine closely whether informed consent can be defended as a bulwark of social trust is the problems facing more classical arguments for informed consent. To be brief, the familiar point that patients know best or care the most, and most effectively, about themselves clearly works only for some of the circumstances in which commonsense morality demands informed consent. ${ }^{1}$ Autonomy-based arguments for informed consent are often considered circumstance-independent, but their validity is now in serious doubt. ${ }^{1} 37{ }^{38}$ By contrast, trust is clearly highly necessary and the need to protect it is increasingly being used to justify informed consent across circumstances-even when other considerations fail. As Jackson says,

While the need to win patients' trust varies according to circumstances, the need to maintain their trust, to prevent them from becoming disillusioned about the trustworthiness of their doctors and nurses, is more constant. You may not expect to see this patient again. But the next doctor or nurse who does may have to overcome the legacy of mistrust you have engendered. And then too there are the third parties, who are observing you, to consider: the patients' relatives, your fellow doctors, nurses, trainees and ancillaries, whose trust... may be undermined. ${ }^{21}$

Bok may concur: 'It is far harder to regain trust, once lost, than to squander it in the first place. ${ }^{10}$ And O'Neill, who has 
dubbed autonomy 'the emperor's new clothing,' seems to instate trust in its stead:

Autonomy has been a leading idea in philosophical writing on bioethics; trust has been marginal. This strikes me as surprising... Trust surely is more important, and particularly so for any ethically adequate practice of medicine, science and biotechnology. ${ }^{2}$

\section{CHALLENGING THE TRUST-PROMOTION ARGUMENT}

Given the appeal of grounding informed consent in trust, it is interesting to examine how much the simple trust-promotion argument can or cannot substantiate commonsense intuitions about informed consent. Let me start this discussion by raising a few challenges for the argument. If successful, they expose the inability to nest standard informed consent requirements in this simple formulation of the concern for trust. Other approaches to informed consent, or to trust-promotion, may underlie more successful arguments.

\section{Breaching trust secretly}

The following imaginary situation illustrates that sometimes, informed consent does not protect trust.

The patient is asleep. The room is empty. It is late at night. The IV is connected, and the nurse could slip some unwanted, potent, and-in all likelihood-medically beneficial drug into the bag. There would not be adverse drug interactions or physical traces and chances are that the drug would improve the patient's life overall, and not just medically. No one except the medical team would know that a potent drug was administered despite the patient's refusal. In such circumstances, imposing treatment is more likely than not to be medically and otherwise beneficial. It would also clearly violate informed consent norms. While the requirement of informed consent might not obtain across the board, whether it obtains in a given context intuitively seems rather independent of whether the intrusion took place late at night. However, given that no one would know about an intrusion that takes place late at night, such an intrusion would be unlikely to diminish public trust. It is possible, then, to violate standard informed consent requirements without undermining public trust in the medical community.

Some may explain that the only reason why public laws and regulations surrounding informed consent cannot permit imposing care "late at night only" is that the public, noting these public laws, would then lose its trust in the medical system; and to hide those laws would violate publicity requirements. This answer fails to substantiate the putative moral duty of informed consent as commonsense morality construes it; only the moral duty to create and protect laws and regulations that demand informed consent. Commonsense informed consent requirements are usually understood to be about how doctors and nurses should behave, and not only about how to tell them to behave. $^{1}$

Another response to my imaginary situation challenge is that when it seems clear to doctors that no one will discover the imposed intervention, still someone will occasionally discover it. Then, precisely because earlier it was unlikely that anyone would discover it, people might suspect that far from the public eye, doctors impose care left and right. Public trust in doctors could sharply decline. Thus, the reply goes, doctors must never impose care-not even in seemingly 'safe' conditions.

This ingenious response (suggested to me by Dan Wikler, evoking ideas from R F Harrod) cannot be quite true-or the following clearly-false claim would be true: A perfectly rational egoist who stands to gain a lot from cheating people, but who stands to gain much more from maintaining their trust, will never cheat them, even when she has strong subjective reason to expect to get away with it; if ever she were caught cheating on occasions when she could expect not to, she would lose too much public trust in her. Surely this claim is hyperbolic. Sometimes the subjective probability of being caught and the expected loss from being caught are low enough to keep the net prospect from cheating positive, and cheating, advantageous for an egoist. Similarly, sometimes the subjective probability for doctors of being caught imposing beneficial care is low enough to keep the net social prospect positive.

\section{Too much trust}

Society and the medical system could not function without a minimum of trust. But it may remain the case that we can afford to lose some trust. In fact, champions of informed consent accept that there can be such a thing as too much trust in doctors. Many depict the era of medical paternalism as one of irrational, excessive trust in doctors; and many lament the therapeutic fallacy, which involves research participants' excessive trust that medical investigators aim primarily to benefit them. Carolyn McLeod concludes,

[whether] to hammer home to the public the message that physicians and other medical professionals actually help people and care about them... is morally appropriate would... depend on whether the resulting trust would be justified. In general, cultivating trust is only wise if trusting would be wise in the circumstances. $^{23}$

This conclusion is not quite right. Cultivating irrational trust can also improve social cooperation (directly, or by encouraging third parties' rational trust), a potentially strong reason to cultivate irrational trust. But McLeod is surely right that, whether we should cultivate social trust in medical institutions depends on whether we are above, or below, the (local) optimum of such trust. This holds whether we define that optimum in terms of the rationality of placing such trust, the social utility of its existence, or any other standard.

Some writers for whom informed consent matters because trust matters seem convinced that we happen to be approaching a dangerous level of distrust. We are, so to speak, far below optimum. However, little evidence supports such a bold claim. What needs to be shown is that rising distrust is pushing medical systems close to the brink of collapse, or something in that ballpark. Only that, it seems, might offset the combined badness of countless compromises of clinical outcomes that nonpaternalistic practitioners make every day.

O'Neill, who discusses a crisis of trust in the medical system, admits other times that in the general population, many of those who supposedly lack trust in fact use that system regularly. Nor does she seem able to name any other truly major harm from increasing distrust. Bok does point out some damages, especially 'difficulties in gathering census data and other types of information,' as well as some public suspicion of medical investigations. ${ }^{10}$ But are these damages really greater than the damage of countless wasted opportunities to improve clinical outcomes by foisting beneficial care on unwilling patients, a damage wrought by informed consent? If our intuitive disapproval of imposed care is justified, another ground must make it justified.

The reality of our location in relation to the trust optimum is probably that some of us have insufficient trust in doctors while others have excessive, naïve trust in them. One possibility therefore would have been to institute fully informed consent for 
some of us and not for others. But different informed consent policies (given the statistical correlation with distrust, perhaps more rigorous informed consent standards for African-American research participants than for Caucasians? $)^{27}$ would have obviously been problematic in their own right, partly for seeming unfair and further undermining trust.

\section{Damage to trust}

In some ways, standard informed consent requirements diminish interpersonal trust in clinicians and investigators. Their overall impact on trust in the medical system may turn out to be mixed, or negative.

Since the culture of informed consent often presents the caretaker as someone to be suspected and monitored closely, some worry that it 'crowds out' interpersonal trust in the doctor. $^{2} 151939$ Consider a doctor who tells her patient, 'Don't trust me: you decide!' Her words could carry two effects. As an invitation of audit and answerability, they make her more trustworthy and potentially more trusted. ${ }^{40}$ However, as a statement that she and her colleagues should not be trusted, they may decrease trust in them. Empirical researchers, not arm-chair bioethicists, ought to determine which effect is stronger.

Furthermore, if some (negative) factors might deter patients and research subjects or directly engender distrust, full disclosure must include them-with clear risk to trust. For this reason, it is unclear that practitioners and investigators who lay out every last detail of their conflicts of interest, for example, increase patients' and candidate subjects' trust in them. Imagine, 'I will probably launch my career and earn a fortune if you undergo this experimental operation, but in all honesty I would not recommend it unless it were promising for you.' The overall effect is complex, not purely assuring. It is true that if the public knew that disclosure was full, this would give it full assurance that nothing worse was hidden from it. But the public can never be sure that the disclosure was full. It may suspect that worse details remain hidden.

Indeed, frightening risks, juicy tales of doctors' and investigators' conflicts of interests, and other disclosed information might remain in the public memory and diminish many people's trust, long after the mundane fact that they were openly disclosed disappears from memory. By analogy, suppose that the worst sides of good humanitarian organisations were regularly disclosed to potential donors and the general public. A constant trickle of gossip on the inevitable petty fights among humanitarian workers, their little failures and occasional corruption was constantly on the news, open for demagogical opponents to exploit. It is far from clear that this full disclosure would boost public trust in humanitarian organisations. Short-term and longer-term trust in them has waned when they released such stories. ${ }^{41}$ Perhaps the public should have realised that transparency warrants trust. But the public doesn't.

The same part of standard informed consent requirements may also make clinicians and investigators less trustworthy. Full disclosure sometimes renders investigators overconfident in their righteousness-and consequently less trustworthy. ${ }^{42} 43$ This might turn out to apply to full disclosure of the risks from research participation and to other aspects of informed consent.

Finally, when trust starts out very low, the standard consent process may diminish it further. In interviews with African-Americans about medical research, participants believed the purpose of the consent document was to protect hospitals and doctors from any legal responsibility. As one participant stated, 'If you give consent, then you don't have any legal rights. When you sign that paper, you sign all of your rights away because they have disclaimers all neatly typed up, reviewed by their lawyers to protect themselves from being sued. ${ }^{, 27} 29$

If indeed standard informed consent practices in some ways damage trust, then their net effect on trust could turn out to be negative, a matter for empirical investigation. Interestingly, 'the decline in public (confidence in, and respect for, doctors) after 1950 coincided with the call for accountability of the medical profession. $^{40}$ One possible explanation for that decline would be that informed consent and other accountability measures had a negative net effect on trust in doctors.

\section{Overemphasising trust}

Intuitively, it seems justified to adhere to certain practices even at the price of damage to trust. Take the following, motley assortment of examples. 'Participatory democracy, better public education, the attention of the media and mistrust of authority and experts in general-all have weakened the trust relationship', especially between doctors and patients ${ }^{19}$ - but clearly it remains permissible to maintain participatory democracy, better public education and so forth: we should be willing to live with some loss of trust in doctors. Likewise, although atheists may be America's most distrusted minority, ${ }^{44}$ it remains permissible to hire openly atheistic physicians for American communities, even if that turned out to undermine communal trust in doctors. Finally, 'the sense of trust is diminished as the doctor-patient relationship becomes more specialised, impersonal, and shortlived, 11202440 and yet surely it remains permissible to offer patients specialist care. If the need to maintain trust is not strong enough to transform our obligations to cultivate participatory democracy, hire atheists and offer specialist advice, why assume that it is strong enough to generate informed consent requirements which commonsense morality construes as powerful enough to cost patients their lives?

\section{Underemphasising trust}

One response to some of the challenges noted so far would have been to say that standard informed consent policies promote trustworthiness, not trust. Naïve patients trust practitioners, but they only have reason to trust trustworthy ones. Bigots distrust atheist doctors, but they have reason to trust many, who are trustworthy. Indeed, for Onora O'Neill, 'Informed consent requirements are one aspect of trustworthy institutions' (my italics). ${ }^{2}$

This response, however, would raise a different challenge. How is improving trustworthiness addressing the bad outcomes of low trust? As O’Neill admits, trustworthiness does not always increase trust: 'We may need more than improvements in trustworthiness if we are to have any restoration of trust. ${ }^{2}$ For O'Neill, justified informed consent works only with reasonable people. Obviously, however, they need not constitute the majority. If the problem is real-world distrust crises, why increase trustworthiness, which may turn out to increase trust only in an ideal world, populated by reasonable people? Shouldn't we resolve the actual crisis?

Conceivably, O’Neill would deem it (utility-maximising, but) unduly intrusive to manipulate people into trusting doctors who are worthy of distrust. A Kantian, she may prefer a policy of giving people sound reason to trust doctors-say, by never deceiving them but instead letting them decide on their own how much to trust doctors. This, nevertheless, would already assume that doctors have strong independent (Kantian?) reason against manipulating patients into trusting them when they are untrustworthy. This strong independent reason may then ground informed consent, for example the prohibition on 
manipulating patients, sufficiently, leaving no role for the case from trust-promotion.

\section{Self-distrust}

There is no informed consent if coming to see the doctor cedes sovereignty over one's body, and the doctor can then proceed with intervention despite one's concurrent refusal of that intervention. Even if the decision to come see her was informed and voluntary, commonsense informed consent standards are violated. Nonetheless, some patients would find such violations of standard informed consent requirements an attractive means of self-commitment. So their trust and medical adherence would only increase. Let me illustrate.

Imagine a devout Catholic who expects to see a decline in her currently strong faith in the course of prolonged treatment. She may expect the nuns who treat her to remain closer to her present world view throughout, including when it is time to either continue or stop the treatment in the light of religious considerations. It would make sense for her to write a binding advance directive that allows the nuns to force treatment on her future self, autonomous as she may be in the future. And it would make sense to skip form filling by choosing to get care at a convent that imposes Catholic care on its patients.

Or picture a capacitated and self-conscious, but also obstinate patient who knows that in the event of disagreement with the medical team, she would insist even without warrant. Knowing that about herself before visiting the clinic, she may find imposed care in violation of standard informed consent requirements attractive, as self-binding that would help her fulfil her true (in this case) future desires.

A worry we noted earlier, that without informed consent patients would stay away from clinics because coming there would risk unwanted care, may therefore conflate two decision nodes of these patients. One decision takes place early, and it concerns whether to come see the doctor. Another occurs late, and concerns whom to follow, the doctor or oneself, when disagreement with the doctor arises. Informed consent protects the freedom of the second decision, but that need not affect the first decision.

While usually people trust their own future selves more than they do doctors, this is not a conceptual truth. There may be pockets where such extreme alienation from one's expected future instructions are commonplace. There, trust-promotion would count against standard informed consent requirements.

\section{Trust and small lies}

As mentioned, Bok objects to deceptive psychological research among other things because it impedes trust in scientists and psychologists:

to the extent that [research participants] learned, after the fact, of deceptive studies such as the one to which they had unwittingly been subjected, they would have greater reason than before to be skeptical of the hospital in question... and possibly of health professionals more generally. Such doubts could add to their reluctance to seek medical help in the future and to speak candidly enough with health professionals to receive the best possible advice. ${ }^{101145}$

I doubt that psychological research really undermines subjects' trust in these other respects. As Bok mentions, most subjects of such research are psychology students. This population seems to use medical and psychological services no less than the general public.
Bok cites only rather limited negative outcomes from the often trivial deceit of psychology students-namely, that 'college students, who supply the majority of the subjects for social science research, have developed their own defensive strategies to confound investigators targeting them for deceptive research.' She uses these outcomes as grounds for far-reaching conclusions:

Thus, for professionals, as for public servants, it is more important than ever to win back the active trust that they no longer can count on receiving automatically. Moreover, winning this active trust requires them to conduct themselves in a way that leaves no doubt about their acceptance of ordinary standards of honesty and fair treatment. ${ }^{1011}$

The sense of urgency informing the latter quote is unwarranted by its rationalisation in the quote that preceded it. Small lies rarely translate into full distrust of everything someone says or does.

Take another example of a lie small enough to leave trust in place. Jackson, who thinks doctors should be told never to lie to patients lest trust in doctors diminishes, concedes, 'You may brush aside a patient's apology for calling you out in the night with 'No problem!' however unwelcome the call.' Jackson's response to the challenge is that these are hardly lies: 'No one relies on such conventional expressions as indicative of a person's real feelings..." ${ }^{4}$ But the challenge persists, because even if some patient were known to take such statements literally, it would remain morally permissible, or praiseworthy, to answer 'No problem!'

Bok's and Jackson's reasoning here may misconstrue the nature of trust: 'trust is generally a three part relation: A trusts B to do $x$ (or with respect to $x$ ). ${ }^{46}$ Psychology students who were deceived during research might stop trusting psychology researchers to tell study participants the truth during trials; they could continue to trust them to write truthful articles and to be caring and truthful practitioners. ${ }^{47}$ Patients who see that the physician who answers 'No problem' is tired might lose trust in her polite answers, but these patients' trust in her dedication and professionalism may grow.

Bok also cites examples of specific deceitful studies which had deep adverse effects on subjects' and on the public's trust in investigators. Nancy Kass and colleagues are of the same mind: 'Examples from the past highlight that abuses of human subjects have a lasting and devastating effect on individual's trust of biomedical research, and also on entire communities. ${ }^{5}$ Both are right that the grossly abusive breach of trust in Tuskegee, or in studies that stigmatised non-cognisant participants, may have had a crushing effect on communities' trust in researchers. But that does not show that very minor breaches of trust like the ones involved in most psychological research and corrected shortly thereafter have a similar effect. Tuskegee-scale violations can undermine trust in the basic decency of trust violators and hence in virtually anything they and their professional communities do or say. But deceit in psychological research rarely involves such violations. It violates standard informed consent requirements without jeopardising public trust in the system.

\section{Trust and pertinent information}

Fully informed consent to risky interventions requires, among other things, disclosure and/or comprehension of the relevant risk, and of some other pertinent facts. To justify the standard requirement of informed consent, the need for trust would have had to justify full disclosure or comprehension of all such facts. 
Nevertheless, disclosure or comprehension of such pertinent facts might be unnecessary for keeping doctors and investigators either trusted or trustworthy. What seems more necessary is easy access to a full account of the facts, should the patient or study participant decide to 'audit' her caretaker or investigator. Why? Because the mere possibility of an audit may deter caretakers and investigators from abuse-for the same reasons that audit possibilities deter abusers in general: they make abuse risky. It follows that if rational clinicians and investigators know that patients and study participants have full ability to kick off an audit, and no inhibition about doing so, leading to potentially severe penalties, then those patients and study participants are protected from abuse. They can afford to trust medical and research institutions not to abuse them and thus enlist in trials and so forth. This trustworthiness is accomplished without required disclosure or comprehension of all pertinent risks.

\section{Trust and competence}

What commonsensical informed consent requires is highly sensitive to the patient's (or the study participant's) level of competence for rational decision-making. Fully competent patients enjoy a right to fully informed consent. Patients with compromised decisional capacity are offered something very different: a proxy decision-maker, presumed-consent decisions made by others, or a best-interests test.

The trust-promotion argument is less sensitive to considerations of patient competence. Consider patients with paranoid schizophrenia. Many lack competency for rational decisionmaking and therefore lack some informed consent rights. On the other hand, because these patients are distrustful, considerations of trust-promotion may apply to them in full force, perhaps more than to other patients. If the need to protect trust provided a sufficient justification for informed consent (as the trust-promotion argument says it does), then, contrary to standard formulations of the informed consent requirement, these paranoid schizophrenic patients would probably have to have full informed consent rights. But according to commonsense they lack some consent rights. So the need to maintain trust cannot be a sufficient ground for the standard requirement of informed consent. Something like autonomy-a capacity that many such patients lack-seems more relevant here.

Indeed, children lack autonomy and some rights to consent. But Sissela Bok, who emphasises the role of truthfulness and truly informed consent for protecting trust, demands truthfulness even for children - as a matter of 'trust in the family."11

It might be replied (as one referee for the journal has) that most of us feel more secure if we know that, should we come to have paranoid schizophrenia, we would be treated with drugs against our wish. On this understanding of the argument, it is the trust of people in general that matters, not the trust of the people who have already developed their paranoia, perhaps because, as the referee put it, 'they are few, we are many.' However, commonsense morality does not take the rules governing decision-making for incapacitated patients to depend primarily on the proportion of incapacitated patients in the population, for example, on whether there are relatively many, or only a few, paranoid schizophrenic patients.

\section{Sacrificing for trust}

According to commonsense morality, when a named person is in need of being rescued, we should rescue her. Normally we should not abandon her. Moreover, we should rescue her even when her abandonment would have reserved scarce resources for rescuing a few more people in the future. One worry about grounding the standard informed consent requirement in trust promotion is that the requirement then regularly recommends what those relying only on trust to ground informed consent must take to be the abandonment of a patient in need. Envisage a patient who needs care now, but has misguided wishes about her care. Furthermore, her doctors happen to support the trustpromotion argument and to see it as the sole valid ground for informed consent. They accept her wishes simply to preserve social trust in the medical system. What the doctors do would seem to abandon a named individual in order to preserve social trust in the medical system. Contrary to commonsense norms about rescue, they abandon her for the sake of other social goals, including unidentified patients' care. They omit to provide what they take to be valuable care for a sick patient now, only as a means to preserving trust in the system, for other, unidentified patients' sakes. Commonsense morality likes to hold that a clear and imminent danger for a concrete patient normally takes first priority-even if diminished trust in the system would cost more future patients direly.

Of course, outside this stylised example, even doctors who see trust promotion as a sufficient ground may accept other grounds for informed consent. Still, the stylised example helps by questioning whether the fact that there are benefits to future patients from the preservation of trust would warrant informed consent policy even absent other valid grounds. The trustpromotion argument says that it would.

\section{Trust and prior commitment to informed consent}

The very need to preserve patients' trust in the medical system may presuppose independent reasons to condition medical intervention on consent. The trust of patients and research subjects in that system would have been far less important if doctors forced citizens to undergo checkups and potential treatment or experiments-in violation of standard informed consent requirements. Our moral repugnance at this prospect and our consequent reliance on patients and research subjects to trust physicians and approach them voluntarily presuppose at least some parts of the standard requirement of informed consent, and cannot fully ground it.

An implication is that, strictly speaking it is false that only if the trust that is placed in investigators is deserved can the research enterprise survive. ${ }^{5}$ Outright coercion or naïve trust could have sustained the research enterprise even without deserved trust. We need deserved trust in researchers and practitioners only given some prior commitment to informed consent. But if we have that commitment, trust-building might not be our most fundamental ground for informed consent.

\section{CONCLUSION}

The argument from trust-promotion to the standard informed consent requirement initially appeals. It dovetails nicely with recent insights not only on the grounds for informed consent but on the clinical value of patient-doctor communication, impediments to minority health, the social determinants of health, and social capital. However, this argument faces serious challenges:

1. Breaching trust secretly: Intuitively, violations of standard informed consent requirements continue to be wrong even when clearly no one will discover them and so the public's trust is not at risk.

2. Too much trust: According to commonsense morality, there can be such a thing as too much trust in physicians, so it is not always a strength of informed consent that it promotes trust. 
3. Damage to trust: Standard informed consent practices like full disclosure may turn out to diminish interpersonal trust in doctors, so their impact on overall trust in the medical system is mixed and potentially negative.

4. Overemphasising trust: Otherwise perfectly legitimate policies can increase distrust simply because people respond unreasonably. Intuitively, such distrust rarely provides sufficient reason to avoid these policies.

5. Underemphasising trust: If informed consent promotes trustworthiness more than trust, the question arises how informed consent addresses lack of trust.

6. Self-distrust: Some patients may be happy to undergo future unwanted treatment, for example, if they currently value a certain treatment but they fear that they would come to resist. In such patients, the expectation of certain breaches of standard informed consent might increase trust.

7. Trust and small lies: Deceitful psychological research often violates standard informed consent requirements, but these typically small lies are unlikely to undermine trust in the profession in general.

8. Trust and pertinent information: Standard informed consent requires comprehension of facts about major risk and so forth; trustworthiness, only easy access to those facts, as an auditing device.

9. Trust and competence: The standard requirement of informed consent is very sensitive to the patient's level of decision-making capacity. The need to maintain trust, much less sensitive.

10. Sacrificing for trust: Intuitively, it is problematic to sacrifice a currently needy person for the sake of future benefits to others. But that is what an argument from trust-promotion alone tells us to do.

11. Trust and prior commitment to informed consent: Patient trust would have been far less important if physicians regularly forced citizens to undergo checkups and potential treatment or experiments-in violation of informed consent. Our moral repugnance at this prospect and our consequent reliance on patient trust presuppose something like the standard requirement of informed consent, and cannot fully ground it.

One may also conceive additional commonsense-based challenges to the trust-promotion argument. ${ }^{1}$ How should we respond to all? Should we discard that argument altogether? Should we accept a revised version? My own guess is that some challenges could not be met. They could be addressed under a revised requirement of informed consent which would differ somewhat from the standard, fully-commonsensical requirement. ${ }^{1}$ Given my further position, that other defences of the standard requirement fail, we should probably explore better versions of that requirement, as well as hitherto under-explored grounds for it. ${ }^{48}$

We should also develop arguments that link trust-promotion with informed consent differently than the schematic argument I explored does. For example, the need for trust-promotion may fail to ground (standard) informed consent requirements on its own but prove necessary or sufficient in conjunction with additional considerations. Bioethicists who link informed consent and trust should put forward lucid formulations of their determinate arguments, for the community to assess.

Acknowledgements I would like to thank an audience at Harvard Medical School, Leah Price, Sissela Bok, and anonymous referees for helpful comments on previous versions.

Funding Edmund J. Safra Center for Ethics Faculty Fellowship, 2010-11.

\section{Competing interests None.}

Provenance and peer review Not commissioned; externally peer reviewed.

\section{REFERENCES}

1 Eyal N. Informed consent. In: Zalta EN, ed. Stanford encyclopedia of philosophy. 2011; http://plato.stanford.edu/archives/fall2012/entries/informed-consent/ (accessed 22 Nov 2012).

2 O'Neill O. Autonomy and trust in bioethics. Cambridge: Cambridge University Press, 2002a.

3 Tännsjö T. Coercive care: the ethics of choice in health and medicine. London: Routledge, 1999.

4 Jackson J. Truth, trust and medicine. Londonand New York: Routledge, 2001.

5 Kass NE, Sugarman J, Faden R, et al. The fragile foundation of contemporary biomedical research. Hastings Cent Rep 1996;26:25-9.

6 Faden RR, Mastroianni AC, Kahn JP. Beyond Belmont: trust, openness, and the work of the advisory committee on human radiation experiments. In: Childress JF, Meslin EM, Shapiro HT, eds. Belmont revisited: ethical principles for research with human subjects. WashingtonDC: Georgetown University Press, 2005:41-54.

7 Tännsjö T. Consent in the clinic and in research—should there be a difference? Forthcoming.

8 Sreenivasan G. Does informed consent to research require comprehension? Lancet 2003;362:2016-18.

9 Mastroianni AC. Sustaining public trust: falling short in the protection of human research participants. Hastings Cent Rep 2008;38:8-9.

10 Bok S. Shading the truth in seeking informed consent for research purposes. Kennedy Inst Ethics J 1995;5:1-17.

11 Bok S. Lying: moral choice in public and private life. New York: Vintage, 1999

12 Flanigan J. Three arguments against prescription requirements. J Med Ethics 2012:38:579-86.

13 Grady C, Hampson LA, Wallen GR, et al. Exploring the ethics of clinical research in an urban community. Am J Public Health 2006;96:1996-2001.

14 Joffe S, Truog RD. Consent to medical care: the importance of fiduciary context. In: Miller FG, Wertheimer A, eds. The ethics of consent. New York: Oxford University Press, 2010:347-74

15 Pellegrino ED, Thomasma DC. The virtues in medicine. New York: Oxford University Press, 1993.

16 Govier T. Social trust and human communities. Montreal\& Kingston: McGill-Queen's University Press, 1997.

17 Zaner RM. The phenomenon of trust and the patient-physician relationship. In: Pellegrino ED, Veatch RM, Langan JP, eds. Ethics, trust and the professions: philosophical and cultural aspects. Washington, DC: Georgetown University Press, 1991:45-63.

18 Richardson HS. Moral Entanglements: The Ancillary-Care Obligations of Medical Researchers. New York: Oxford University Press, 2012.

19 Pellegrino ED. Trust and distrust in professional ethics. In: Pellegrino ED, Veatch RM, Langan JP, eds. Ethics, trust, and the professions: philosophical and cultural aspects, 1991:69-85.

20 Rothman DJ. Strangers at the bedside: a history of how law and bioethics transformed medical decision making. New York City: Basic Books, 1991.

21 Jackson J. Promise-keeping and the Doctor-Patient relationship. In: Gillon R, ed. Principles of health care ethics. Chichester: John Wiley \& Sons, 1994:489-97.

22 Parfit D. On what matters. Vol. I. New York: Oxford University Press, 2011; http:/l plato.stanford.edu/archives/spr2011/entries/trust/ (accessed 22 Nov 2012).

23 McLeod C. Trust. In: Zalta EN, ed. The Stanford encyclopedia of philosophy. 2011 ed, 2011.

24 Wolpe PR. The triumph of autonomy in American bioethics: a sociological view. In: DeVries R, Subedi J, eds. Bioethics and society: constructing the ethical enterprise. EnglewoodCliffs, NJ: Prentice-Hall, 1998:38-59.

25 Kaplan SH, Gandek B, Greenfield S, et al. Patient and visit characteristics related to physicians' participatory decision-making style. Results from the Medical Outcomes Study. Medical care 1995;33:1176-87.

26 Schuck PH. Rethinking informed consent. Yale Law Journal 1994;103:899-959.

27 Corbie-Smith G, Thomas SB, Williams MV, et al. Attitudes and beliefs of African Americans toward participation in medical research. J Gen Intern Med 1999;14:537-46.

28 Wood CG, Wei SJ, Hampshire MK, et al. The influence of race on the attitudes of radiation oncology patients towards clinical trial enrollment. Am J Clin Oncol 2006:29:593-9.

29 Freimuth VS, Quinn SC, Thomas SB, et al. African Americans' views on research and the Tuskegee Syphilis Study. Soc Sci Med 2001;52:797-808.

30 Corbie-Smith G, Thomas SB, St George DM. Distrust, race, and research. Arch Intern Med 2002;162:2458-63.

31 Jacobs EA, Rolle I, Ferrans CE, et al. Understanding African Americans' views of the trustworthiness of physicians. J Gen Intern Med 2006;21:642-7.

32 Shaz BH, Hillyer CD. Minority donation in the United States: challenges and needs. Curr Opin Hematol 2010;17:544-9.

33 Siminoff LA, Arnold R. Increasing organ donation in the African-American community: altruism in the face of an untrustworthy system. Ann Intern Med 1999;130:607-9. 
34 Krakauer EL, Truog RD. Mistrust, racism, and end-of-life treatment. Hastings Cent Rep 1997;27:23; discussion 23-5.

35 Blackhall LJ, Frank G, Murphy ST, et al. Ethnicity and attitudes towards life sustaining technology. Soc Sci Med 1999;48:1779-89.

36 Institute of Medicine. Unequal treatment: confronting racial and ethnic disparities in health care. Washington: National Academy Press, 2002.

37 Manson NC, O'Neill O. Rethinking informed consent in bioethics. Cambridge: Cambridge University Press, 2007.

38 Kihlbom U. Autonomy and negatively informed consent. J Med Ethics 2008:34:146-9.

39 Power M. The audit society. Oxford: Oxford University Press, 1997.

40 Betz AM, O'Connel L. Changing doctor-patient relationships and the rise in concern for accountability. Soc Probl 1983;31:84-95.

41 Heilprin J. Global Fund Rethinks Transparency Policy After Corruption Scandal Huffington Post, 2011.
42 Cain DM, Loewenstein G, Moore DA. Coming clean but playing dirtier: Perverse consequences of disclosing conflicts of interest. In: Moore DA, Cain DM, Loewenstein G, Bazerman MH, eds. Conflicts of interest: challenges and solutions in business, law, medicine, and public policy. New York: Cambridge University Press, 2005:104-25.

43 O'Neill O. A question of trust: 2002 BBC reith lectures. Lecture 4: trust and transparency. Cambridge: Cambridge University Press, 2002b.

44 Edgell P, Gerteis J, Hartmann D. Atheists as "Other": moral boundaries and cultural membership in American society. Am Sociological Rev 2006;71:211-34.

45 Lawson E. Informational and relational meanings of deception: Implications for deception methods in research. Ethics Behav 2001;11:115-30.

46 Hardin R. Trust and trustworthiness. New York: Russell Sage Foundation, 2002

47 Bortolotti L, Mameli M. Deception in psychology: moral costs and benefits of unsought self-knowledge. Account Res 2006;13:259-75.

48 Eyal N. Reconciling informed consent with prescription drug requirements. J Med Ethics 2012;38:589-91. 